\title{
Compromís i denúncia en el teatre de Lluïsa Cunillé: Geografia i El carrer Franklin
}

\section{Commitment and Denunciation in the Theater of Lluïsa Cunillé: Geografia and El carrer Franklin}

\author{
Ana Prieto Nadal \\ SELITEN@T (UNED) \\ apriet22@gmail.com \\ Recibido: Abril de 2016. Aceptado: Junio de 2016
}

\begin{abstract}
Resum: En les seves obres més recents, Lluïsa Cunillé ha dirigit la mirada cap a qüestions polítiques i socials d'actualitat; els exponents més clars d'aquesta progressió cap a un major compromís i una major presència, en el seu teatre, dels conflictes que caracteritzen la nostra societat són Geografia, la seva proposta per al tríptic Fronteres (2014), i El carrer Franklin (2015), ambdues estrenades al Teatre Nacional de Catalunya. En aquestes peces, la dramaturga s'ocupa de temes com la corrupció, el nepotisme, l'especulació immobiliària, la crisi econòmica i cultural, i també de la manera com el joc d'interessos de les entitats bancàries i l'avarícia personal dels seus dirigents han sumit la ciutadania en una situació crítica de difícil solució. El teatre de Lluïsa Cunillé contribueix, per la manera com mostra les formes de vida material i el món psíquic dels personatges, a explicar les lògiques que orquestren les transformacions del nostre present social i històric.
\end{abstract}

Paraules clau: Lluïsa Cunillé, El carrer Franklin, teatre contemporani, compromís polític, denúncia.

\begin{abstract}
In her most recent theater, Lluïsa Cunillé has turned her gaze to current political and social issues; the clearest examples of this progression towards a greater commitment and a greater presence of the conflicts that characterize our society are the plays Geografia, her proposal for the triptych Fronteres (2014), and El carrer Franklin (2015), that were premiered in the Teatre Nacional de Catalunya. In these two plays, the playwright deals with issues such as corruption, nepotism, real state speculation, economic and cultural crisis, and the way the game of interests of banks and the personal greed of their leaders have plunged the citizens in a hopeless situation. The theater of Lluïsa Cunillé helps explain the logics that orchestrate the transformation
\end{abstract}


of our social and historical present, by showing the forms of material life and psychic world of the characters.

Keywords: Lluïsa Cunillé, El carrer Franklin, contemporary theater, political commitment, denunciation.

\section{CAP A UNA PROGRESSIVA EXPLICITACIÓ DEL COMPROMÍS POLÍTIC}

El teatre de Lluïsa Cunillé, autora de gran ofici i obra prolífica, sobresurt per la seva insubornable mirada ètica, així com per la seva versatilitat i per un treball marcadament artesanal. Durant més de vint-i-cinc anys de dedicació pràcticament exclusiva a la dramatúrgia, l'autora ha indagat i explorat les potencialitats genèriques i formals d'aquest art.

El seu teatre, sovint considerat críptic, ha estat tradicionalment inclòs dins la tendència del drama relatiu (Batlle 1999: 46), o bé de la teatralitat opaca -la poètica de la sostracció de què parla Sanchis Sinisterra (2002: 140)-, per raó de l'ús d'estratègies discursives de fragmentació i repetició que deixen la interpretació última en mans de l'espectador. Tal com afirma Massip (2004: en línia), es tracta d'una «teatralitat plena de forats, poc interessada (o gens) pels problemes i circumstàncies de l'actualitat, allunyada d'una realitat contingent, centrada en les circumstàncies i els conflictes individuals més que en els col-lectius, amb personatges innominats».

Vet aquí, però, que a partir d'un determinat moment, en obres com Barcelona, mapa d'ombres (2004) i Après moi, le déluge (2007), entre moltes altres, l'autora comença a dotar l'argument d'una major concreció, aportant major referencialitat a les situacions i conferint-li més protagonisme a la paraula com a constructora del relat. Així, d'un diàleg «fragmentari, balbucejant, repetitiu i obert; ple de dubtes i silencis, d'omissions, confusions i interrogants, en la senda del «teatre de l'amenaça» i del silenci eloqüent de Harold Pinter» (Massip 2013: en línia), passa a un discurs més logocèntric. Com diu Albertí, els personatges de Cunillé «Van començar operant en el seu teatre amb la voluntat de construir silencis; ara estan més preocupats per trobar la paraula exacta. Al principi de la seva escriptura les paraules explicaven els silencis, ara els silencis expliquen les paraules» (2008: 11). I paral-lelament a aquesta major ampliació del camp del personatge a través de la paraula, hi ha una major atenció a les problemàtiques actuals.

En les seves darreres obres -també en les d'autoria compartida amb Xavier Albertí i amb Paco Zarzoso-, Cunillé ha atès a qüestions polítiques i socials d'actualitat ${ }^{1}$. Així, a La cantant calba al Mc Donald's (2006) els personatges de Eugene Ionesco, submergits en un context contemporani, serveixen per parlar

\footnotetext{
${ }^{1}$ Per aprofundir en els arguments i les temàtiques de les peces de Lluïsa Cunillé, remetem al nostre llibre sobre el seu teatre (Prieto 2016: 31-74).
} 
de la globalització. En Assajant Pitarra (2007) hi ha una crítica a la política actual, concebuda como un mercat d'ofertes ideològiques desnaturalitzades, $\mathrm{i}$ en El bordell (2008) s'aborda l'etapa de la Transició espanyola, amb el focus posat en quatre personatges que han quedat atrapats en la vivència del cop d'estat del 23-F. La inèdita Islàndia (2009) constitueix un viatge iniciàtic -un drama d'estacions- a l'epicentre borsari de Wall Street, un descens als inferns del neocapitalisme. Dictadura, dins l'espectacle d'autoria múltiple Dictadura-Transició-Democràcia (2010), una única pero bigarrada escena coral amb deixos berlanguians, serveix un esperpèntic i frívol retrat de l'Espanya de 1962, amb tòpics rancis i lemes franquistes, versos de corrandes i cites cinematogràfiques de l'època. L'any 2011 Lluïsa Cunillé va estrenar dues peces breus a l'estranger: Confessions, un encàrrec del Festival Internationale Neue Dramatik (FIND) de la Schaubühne de Berlín, denuncia la utilització, per part dels mass media i la telerealitat, de la intimitat de gent anònima com a material per ser exhibit, jutjat, escarnit i, en suma, consumit i fagocitat per la maquinària mediàtica de la societat de l'espectacle; La vergonya, estrenada a Viterbo en el marc del Festival Quartieri dell'Arte, aborda la qüestió de la consciència ciutadana i el compromís polític a través del retrat d'una dona gran que viu amb la vergonya d'haver-se quedat petrificada en la inacció i el conformisme, en el si d'una societat anestesiada i sumida en un profund somni. La inèdita i mai estrenada Dinamarca (2014) qüestiona, en diàleg intertextual i metateatral amb Hamlet de William Shakespeare, la societat del benestar i el concepte de felicitat o autorealització, i Boira (2014), guanyadora del primer Premi de Textos dramàtics Frederic Roda, constitueix una reflexió sobre el que va suposar el pas del comunisme al capitalisme en el bloc de l'Europa de l'Est i acaba de confirmar la tendència, en la producció més recent de Lluïsa Cunillé, a una major contextualització històrico-geogràfica $i$ al compromís testimonial amb la nostra època en diàleg amb el passat recent. Serenata para un país sin serenos, obra de dramatúrgia compartida amb Paco Zarzoso i estrenada el gener de 2015, posa en primer terme l'especulació immobiliària i els fraus fiscals del president d'un gran club de futbol.

\section{GEOGRAFIA (2014): BLANQUEIG DE MEMÒRIA}

Geografia aborda el tema de la corrupció, no només en els àmbits de la política i l'economia sinó també a nivell cultural, i plasma escènicament diverses acepcions del terme frontera. El TNC va encarregar a tres dramaturgs contemporanis una peça a partir d'aquest concepte tan ric en interpretacions: les fronteres, reals o imaginàries, internes o externes, ens constitueixen i contribueixen a definir-nos i forjar la nostra identitat. El tríptic Fronteres -conformat per Santa Cecília de Borja a Saragossa, de l'argentí Rafael Spregelburd; Frontex, de l'alemany Falk Richter, i Geografia, de la catalana Lluîsa Cunillé- va poder veure's al TNC entre el 14 de maig i el 8 de juny de 2014.

Si la peça de Spregelburd s'inscriu en el gènere de la farsa i la de Richter s'endinsa pels viaranys de l'al-legoria, Geografia situa dos personatges sense nom en un no-lloc, una carretera deserta, amb dues maletes plenes de bitllets. 
La situació pot semblar beckettiana a priori, però és força més explícita que en altres obres de l'autora. L'escenografia, compartida per les tres peces de Fronteres i per tant vertebradora de la proposta, respon ara a la demanda d'immensitat formulada pel director de la tercera obra, Xavier Martínez. Així, es passa de l'espai tancat de la cafeteria de Santa Cecília de Borja a Saragossa a l'espai tancat però en clar conflicte amb l'espai exterior de Frontex, per finalment obrirse a la immensitat de l'espai obert, la carretera secundària poc transitada de Geografia. L'escenografia de Quim Roy es tenyeix de nocturnitat i diverses tonalitats del blau; hi ha un únic fanal encès, i sobre el terra una línia blanca discontínua ens ubica en una carretera. Al soroll de grills que ambienta l'escena nocturna, s'hi suma el d'alguns avions i cotxes que passen i, a l'inici de la funció, el de les rodetes de les maletes arrossegades per un home -Ell, interpretat per Jordi Boixaderas- i una dona -Ella, interpretada per Lina Lambert-; es tracta d'un matrimoni que ha tingut pana en el viatge de tornada d'Andorra i s'ha quedat empantanegat al bell mig d'una carretera poc transitada, en plena nit i amb quatre maletes plenes de bitllets de cinc-cents euros.

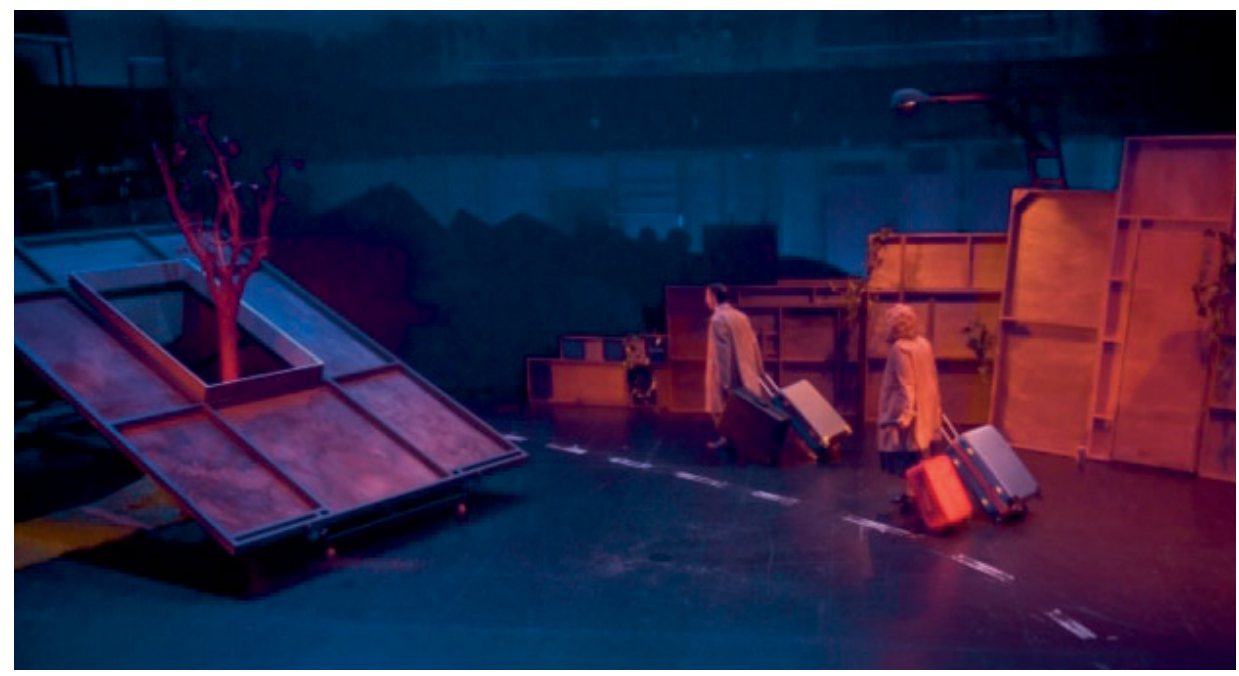

(C) Francesc Meseguer/TNC.

Xavier Martínez, el director de la peça, es va inspirar en el cinema negre americà dels anys quaranta per caracteritzar aquests dos personatges com a éssers liminals, situats en els marges de la legalitat i retratats en el moment de fugir a altres llocs ${ }^{2}$. Martínez considera que aquesta obra constitueix un mapa moral sobre el fenòmen de la corrupció (Graell 2014: 50), i precisa que «La corrupción política es la corrupción de las personas y por tanto de una sociedad

2 Declaracions de Xavier Martínez en el col-loqui postfunció que va tenir lloc el dia 23 de maig de 2014 al TNC, i en el qual van participar, a més d'ell, els actors Oriol Genís i Roser Batalla, la directora Alícia Gorina i l'escriptor Antoni Puigvert. <https://www.youtube.com/ watch?v=jfsZ8SGhJOQ> [Data de consulta: 26 de novembre de 2015.] 
y una cultura enferma. El texto reflexiona sobre el estado agónico de nuestra cultura actual, que parece ir a la deriva» (Sala 2014: 5).

El personatge de l'home, beneficiant-se del seu estatus social, assumeix activament el paper d'infractor fiscal i es revela incapaç d'oposar-se a la tradició familiar de fraus i corrupteles. La seva dona, en canvi, apareix com una corrupta passiva, còmplice alhora que víctima. Involucrada a contracor en una situació delictiva, Ella se sent frustrada pel marasme moral en què es troba immersa; vol recuperar el sentit de la seva vida i tornar a la millor versió d'ella mateixa: la professora d'història capaç de restituir la memòria perduda. Tot i la distància creixent, gairebé abismal, entre ella i els seus alumnes $-\ll \mathrm{A}$ mesura que passen els anys menys els entenc jo a ells i menys m'entenen ells a mi. La nostra és la història d'un creixent i patètic desencontre» (Cunillé 2014: 79)-, li agrada fer classe i pensa que potser hauria de tornar a l'escola pública. Recorda amb nostàlgia entelada d'idealisme el poema que li van recitar els alumnes de l'única escola pública on va treballar fa molts anys, abans de casar-se. Li proposa al seu marit que marxin a l'estranger; el cert és que només podria il-lusionar-se un altre cop amb la seva professió lluny d'aquest país que - diu Ella- fa beure els seus habitants de la font de l'oblit: «Me'n vull anar abans que tornin a retallar els pressupostos d'educació, i al proper pla d'estudis suprimeixin la meva assignatura per sempre com ja han fet amb d'altres» (Cunillé 2014: 84).

Ell, aliè a la crisi de la seva dona, la lloa com a còmplice perfecta, per bé que involuntària, en l'evasió d'impostos: «En tots aquests anys no ho hem fet gens malament. De fet, és el que sabem fer més bé» (Cunillé 2014: 79). Però el conflicte és inevitable, perquè el matrimoni ha arribat a un carreró sense sortida; incapaços de suportar-se, intercanvien insults de bestiari, però sense alçar la veu en cap moment. Es tracten sense la menor delicadesa: Ell frega els bitllets contra l'esquena de la dona, per ofendre-la, i Ella li aixeca un camal dels pantalons i treu la petaca que l'home té amagada sota el mitjó. Forcegen fins que la petaca cau a terra, s'obre i es vessa tot el líquid.

Quan el seu marit l'abandona enmig del no-res, Ella li parla a la seva classe, assumida ficcionalment pel públic a la platea, i exhorta els seus alumnes a deixar el país. En un estat de profunda crisi vital, la dona enyora temps millors en l'ensenyament; d'alguna manera, dóna ja per perdut el seu ofici. Denuncia fins a quin punt ens hem oblidat dels mites fundacionals -les arrels culturals-i els hem substituït per mites neoliberals. En un moment donat esmenta Sísif, que és, des d'Albert Camus, l'heroi absurd per definició, tant per les seves inútils passions com pel seu turment.

Tan absurds com Sísif, els dos personatges de Geografia assumiran el seu destí: Ell persistirà en l'evasió d'impostos, i Ella renunciarà definitivament a ensenyar en un país que menysté la memòria, encara que, això sí, s'endurà la seva part del botí, aconseguit gràcies a les trampes fiscals del seu marit. Així, quan senti el motor d'un cotxe que s'apropa, correrà amb les seves dues maletes cap a una nova vida. Poc després, l'home torna muntat sobre una bicicleta rovellada, s'atura davant el fanal i aconsegueix parlar amb els seus pares pel telèfon mòbil. Com un nen atemorit $\mathrm{i}$ alhora juganer que ordeix una gran mentida com 
a manera d'evadir-se o desfogar-se, s'empesca que li han robat el cotxe i després improvisa que hi ha hagut una revolució a Andorra, fins que es veu obligat a reconèixer que s'ho ha inventat tot. Admet que ha begut una mica, per fer passar el fred, però els assegura que els diners són en un lloc segur. Aleshores ens adonem de quins poden ser els referents reals que han inspirat aquests personatges. Per a Oriol Puig Taulé és ben clar que els qui parlen a l'altre costat de la línia són Jordi Pujol, l'expresident de la Generalitat de Catalunya, i la seva dona, Marta Ferrusola, i que l'evasor d'impostos és el seu fill gran (Puig Taulé 2014: en línia). Pensem que Lluïsa Cunillé ha volgut jugar amb aquests referents d'actualitat, però ha volgut sobretot crear uns personatges sense nom propi que li permetin explorar, com diu Xavier Martínez, el mapa moral de la societat contemporània. El final de la peça ens mostra com l'home arrossega les dues maletes i surt d'escena.

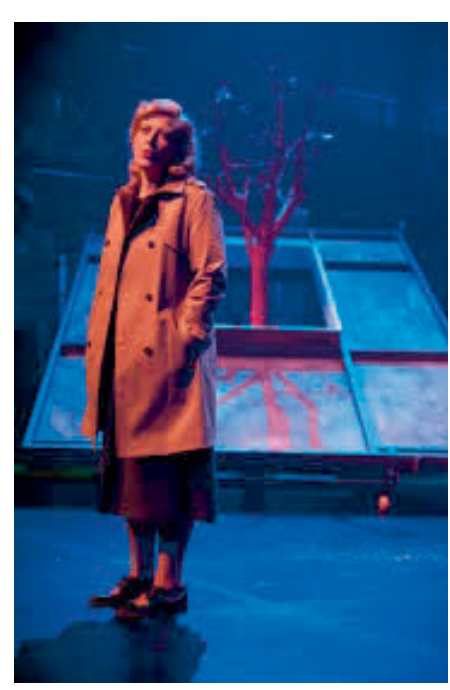

(C) Francesc Meseguer/TNC.

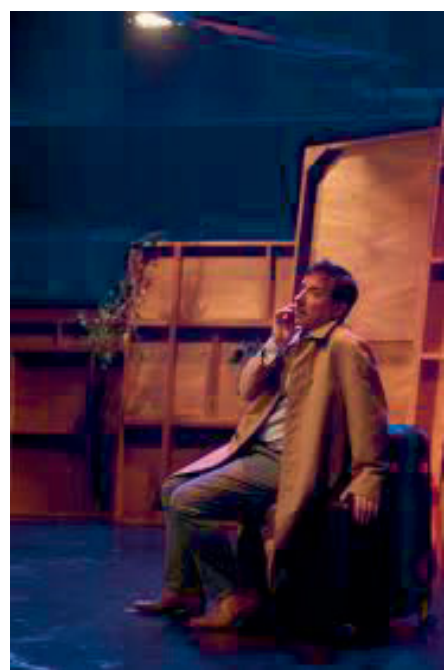

(C) Francesc Meseguer/TNC.

Sobre aquest mapa moral tan dubtós es tracen fronteres de molts tipus. Es parteix d'una frontera concreta, Andorra, i del tràfic de divises, per delimitar després altres territoris. Laura Serra incideix en la utilització de personatges i de referents de la mitologia clàssica com Teseu o Sísif per teixir la història i reivindicar una tradició humanista cada cop més absent del sistema educatiu actual (Serra 2014: 36). La noció de frontera és explorada també en un sentit psicològic i -gairebé es podria dir- existencial: es traça una frontera imborrable -una línia d'impossible retorn- entre allò que van ser els personatges, individualment i com a matrimoni, i el que són ara. També hi ha una frontera social i moral que els separa, i, per la seva banda, Ella creua una frontera interior en deixar d'identificar-se amb la dona que era abans. D'aquesta manera la idea de frontera -com la de corrupció, que no és només política o financera sinó també cultural-genera multitud d'interpretacions i metàfores. 


\section{EL CARRER FRANKLIN (2015) O LA VIDA COM A DESNONAMENT}

Del 2 al 19 de juliol de 2015 es va poder veure al Teatre Nacional de Catalunya, dins el programa del Festival Barcelona Grec 2015, l'última obra de Lluïsa Cunillé programada fins al moment, El carrer Franklin, una esbojarrada farsa que aborda el drama de la crisi econòmica que està redefinint alguns models socials del nostre temps. La direcció va anar a càrrec de Josep Maria Miró, i els intèrprets eren un grup de vells amics -Xavier Albertí, Montse Esteve, Oriol Genís, Lina Lambert i Xavier Pujolràs-, que ja havien protagonitzat ppp (2005), Assajant Pitarra (2007) i La corte del Faraón (2008), entre d'altres peces del tàndem creatiu format per Albertí i Cunillé.

Aquesta peça confirma clarament la tendència de la producció més recent de Lluïsa Cunillé a reflectir, des d'una mirada crítica i de denúncia, la realitat política i social estrictament contemporània. Tot en ella es fa ressó de l'actual depressió econòmica, l'anomenada Gran Recessió, que va començar el 2008. Aquesta crisi s'emmarca dins una crisi econòmica mundial que, en el cas d'Espanya, va comportar el final de la bombolla immobiliària, la crisi bancària de 2010 i l'augment de la taxa d'atur.

El carrer Franklin té lloc al carrer que dóna títol a la peça i que pertany a una ciutat catalana innominada. Cap dels personatges coneix l'origen onomàstic del carrer: tant pot estar dedicat a Benjamin Franklin, polític i inventor del parallamps, com a John Franklin, explorador de l'Àrtic i del Canadà; fins i tot a les escriptores Leonor Franklin i Gertrudis Franklin. Una hipòtesi que sembla plausible és que es tracti del nom de pila del president Roosevelt, que va presidir els EUA durant quatre mandats successius, des de 1932 fins a 1945, i va treure la potència del nord de la pitjor crisi econòmica de la seva història aplicant el seu New Deal a partir de postulats keynesians. Seria més tard, a partir dels anys vuitanta i sota la presidència de Ronald Reagan, quan els Estats Units donarien via lliure a les iniciatives privades i permetrien la desregulació, impulsant així globalment la política liberal propugnada pel thatcherisme -precisament, el gran referent polític d'El carrer Franklin serà Margaret Thatcher-. En qualsevol cas, no importa tant la identificació de la ciutat, o l'existència real del carrer, com el valor simbòlic del fet que l'hodònim sigui un nom americà, clara metàfora del lideratge dels Estats Units en la globalització cultural i econòmica. Resulta molt encertat l'apunt d'Albert Arribas, que posa èmfasi, més que en un personatge històric, en el significat etimològic del substantiu franklin, car en anglès medieval aquest mot feia referència a una persona lliure, és a dir, al contrari d'un serf en el sistema feudal (Arribas 2015: 8).

Els personatges d'El carrer Franklin, en la versió última que va pujar a escena -i que difereix de l'obra publicada, on apareix un sisè personatge, el de la Cantant-, són cinc: el Transvestit, el Marit d'aquest, una Veïna amb sang britànica i thatcherista a les venes, una Activista i un Banquer que resulta ser el governador del Banc d'Espanya.

La bigarrada escenografia d'Enric Planas ens trasllada a finals del segle passat: mobles antics, un telèfon dels anys vuitanta, una màquina d'escriure, etc. Multitud de fòtils, trastos i relíquies -lleixes atapeïdes, un somier, una nevera, un 
piano, una taula de planxar, una bombona de butà, miralls, vitrines, una bicicleta, perruques i fins i tot un maniquí- reposen damunt un terra de rajoles o panots genuïnament barcelonins, amb la flor dissenyada per Josep Puig i Cadafalch i convertida avui en logotip o símbol de la marca Barcelona. També sobresurten, entremig de tanta rampoina, dos elements de mobiliari urbà: una font d'aigua potable i una paperera. D'aquesta manera, la ciutat catalana que en el text restava innominada queda ben definida en la posada en escena.

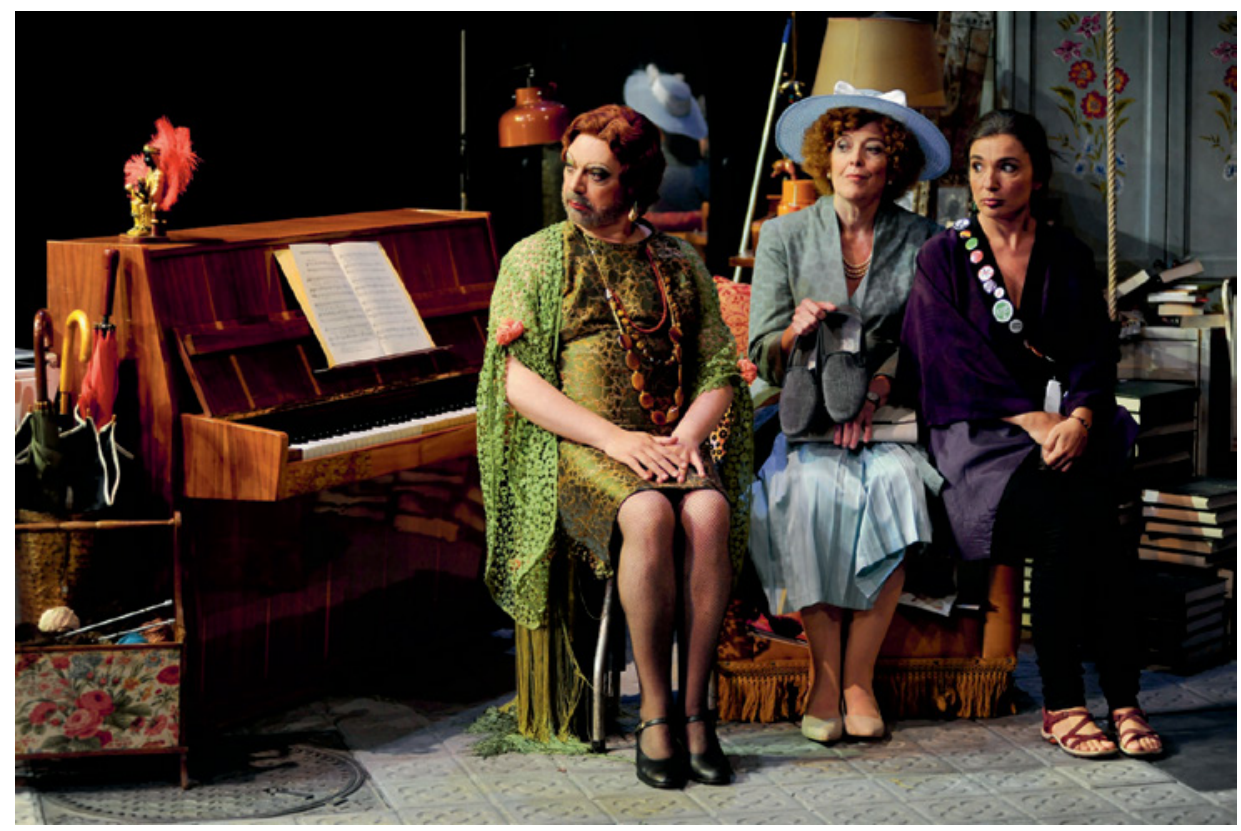

(C) Joan Tomàs/TNC.

El Transvestit lamenta no haver sabut reaccionar amb virulència quan era necessari, i es desfà en insults vehements i metàfores explosives -«Corbs! Bandarres! Rates de claveguera! [...] Però on és el patró dels desnonats, que li posaré dos cards als collons i un fuet encès al seu sant cul?» (Cunillé 2015: 15)- que fan pensar en el llenguatge faller dels personatges d'El alma se sere$n a$, obra escrita per Cunillé i Zarzoso, també sobre el tema de l'especulació immobiliària i la criminalitat de la classe política; en ella, un personatge exclamava que «La vida, además de una gran putada, es un puto desahucio» (Cunillé + Zarzoso 2012: 79).

Entra la Veïna, que torna del consolat britànic. La minúscula urna que duu embolicada amb una bandera britànica descolorida conté una part de les cendres de la seva tieta -ni més ni menys que Margaret Thatcher-: «A cada membre de la família li ha tocat un grapat més gran o més petit segons el parentiu amb la difunta. Tan conservadora com era la tia Margaret, em sembla un disbarat haver-la socarrimat i repartit les seves cendres a pes [...]. Pel que sembla Scotland Yard havia descobert un pla secret xinès per clonar la tia Margaret» (Cuni- 
llé 2015: 17-18). A través d'aquesta Veïna d'origen anglès i neboda de la Dama de Ferro es vehiculen moltes referències al thatcherisme, sens dubte per assenyalar la importància que va tenir la política desreguladora de la primera ministra del Regne Unit entre 1979 i 1990, en sintonia amb la política liberal de Ronald Reagan als Estats Units, en el creixement descontrolat de la indústria financera.

El Transvestit li demana a la Veïna que l'ajudi a escriure una carta al president del Tribunal d'Estrasburg, el Tribunal Europeu de Drets Humans, i li apropa la màquina d'escriure portàtil que hi ha sobre la taula de planxar ${ }^{3}$. En agafar l'urna funerària, al Transvestit li sembla que les cendres de Thatcher pesen massa; i és que no per atzar l'anomenaven la Dama de Ferro. La Veïna adverteix que la màquina d'escriure té diverses consonants espatllades; la rèplica que li dóna el Transvestit - «Mentre tingui totes les vocals senceres, ja anirem fent» (Cunillé 2015: 20)- sembla haver estat dissenyada específicament per a Xavier Albertí, que interpreta aquest personatge ${ }^{4}$.

Entra l'Activista, que, desbordada per l'enorme quantitat d'injustícies que hi ha, decideix agafar el megàfon i fer una crida a la ciutadania: «Ciutadanes! Ciutadans! L'ONG “Aturem la barbàrie global” sol-licita la vostra col-laboració per impedir el desnonament dels veïns del carrer Franklin» (Cunillé 2015: 21). El Transvestit l'avisa que en aquell carrer gairebé tothom ha estat desnonat i pràcticament tots els pisos estan buits. La Veïna és l'única que queda, però si no troba feina i no paga el lloguer del mes vinent serà també desnonada.

Apareix el Marit, un taxista que només treballa els dissabtes perquè comparteix el taxi amb altres sis conductors, i es passa el dia prenent vermuts amb els excompanys del sindicat; afirma portar el bitllet guanyador de la loteria a la butxaca, tot i que el sorteig del dia encara no s'ha celebrat. Els presents, prenent-lo per borratxo, li segueixen la corrent i juguen a simular que són clients del taxi; el Marit assegura que mai ha patit un accident, tret d'una vegada que va atropellar un home: «El cas és que quan el vaig anar a veure l'endemà a l'hospital, l'home em va agrair cent vegades haver-li salvat la vida [...]. Es veu que aquella mateixa nit, com que ell era a l'hospital, la casa no se li va esfondrar a sobre a causa d'una aluminosi traïdora [...] unes setmanes després l'home es va morir igualment d'una infecció hospitalària» (Cunillé 2015: 29).

Irromp el Banquer, amb un aire entre exhaust i desorientat, i s'asseu a una cadira. Després agafa el megàfon de l'Activista per proclamar que és el gover-

${ }^{3}$ La presència d'una màquina d'escriure en un context tecnològic com el nostre no deixa de ser un voluntari anacronisme, molt del gust de Lluïsa Cunillé; es tracta d'un objecte que trobem a diverses obres de l'autora, com ara Passatge Gutenberg (2000) o Una tarda (2001).

4 Albertí, actual director escènic del TNC, ha declarat en no poques ocasions el seu interès per la físicoacústica $i$, en particular, per les sèries vocàliques, capaces de dotar de sentit i intenció un enunciat. En la nostra entrevista publicada en el número 35 de la revista Pausa de la Sala Beckett, Xavier Albertí afirmava: «he viscut sempre molt fascinat pels elements fisicoacústics de la paraula, que dictaminen comportaments. A mi m'ha interessat de vegades abordar un text teatral des de l'anàlisi de les sèries vocàliques i veure com això genera una sèrie d'elements de mobilitat interior» (Prieto Nadal 2013: 102). 
nador del Banc d'Espanya i prometre a tots aquells que treguin el cap per la finestra un crèdit sense interessos o, en el seu defecte, unes vacances pagades a un paradís fiscal. Després de la nul-la resposta a la seva crida, el Banquer conclou que, en efecte, no queda ningú al carrer. En la lògica del sistema, era esperable que la gent no respongués a la crida reivindicativa de l'Activista, però no que desoís els cants de sirena del Banc d'Espanya. El Banquer reconeix davant dels presents que ja no pot concedir cap crèdit a ningú perquè ell mateix ha perdut tot el que tenia. En saber que la Veïna és neboda de Margaret Thatcher, el Banquer troba que hi té una retirada i recorda que va conèixer la primera ministra britànica en una recepció internacional fa molts anys: «la seva tia, en passar pel meu costat, em va dir de sobte: "D'aquí a trenta anys, vostè serà el governador del Banc d'Espanya i jo seré una santa: Santa Margaret dels Mercats. No ho oblidi". La seva tia era una visionària, oi que sí?» (Cunillé 2015: 34). En efecte, la política econòmica de Thatcher, sostinguda pel govern americà, la va erigir en santa patrona dels mercats internacionals: la tenen en els seus altars els especuladors del mercat de divises i els taurons financers.

La Veïna rep una trucada de la premsa, i respon amb contundència que no té res a dir sobre la memòria de Margaret Thatcher. Aprofita per expressar la seva indignació per la precarietat en què es veu immersa, malgrat la seva àmplia formació - «he fet vint-i-dos màsters, i parlo i escric cinc llengües vives i dues de mortes perfectament, i tanmateix no aconsegueixo trobar feina ni de cambrera ni de paleta ni de flamenca en tota la costa mediterrània» (Cunillé 2015: 35)-; afegeix que les úniques coses que no ha empenyorat encara són la seva gata d'angora i una perruca feta amb cabells naturals de la seva tia. Després penja el telèfon i surt d'escena.

El Transvestit agafa el governador de bracet $i$ el porta fins al piano perquè l'acompanyi amb el cant. El Banquer explica que de jove va cantar en un cor Clavé, com a tenor líric. Aquesta referència té la seva gràcia, perquè, a més de vincular el Banquer amb una tradició coral catalana que es va crear al segle XIX per elevar la cultura dels obrers mitjançant la música i el cant sota el lema «Progrés, Virtut, Amor», constitueix una picada d'ullet autoreferencial a la trajectòria teatral dels intèrprets: el 2007 Montse Esteve, Oriol Genís, Lina Lambert i Xavier Pujolràs van protagonizar, al costat de Ricard Borràs, Assajant Pitarra, a les ordres del director Xavier Albertí -aquí un actor més de l'elenc-; en aquell espectacle s'incloïen peces de Josep Anselm Clavé i ells van interpretar La maquinista, Gloria a España, Les flors de maig i La campana.

El Banquer col-loca el Financial Times a manera de partitura sobre el piano i canta El niño judio (1918), de la sarsuela homònima en dos actes, amb llibret d'Antonio Paso i Enrique García Álvarez, i música del mestre Pablo Luna; se selecciona aquí l'inici del quadre segon, en què l'acció se situa al mercat d'Alepo, Jerusalem. Hi ha un evident i hilarant joc de paraules, perquè els mercats dels quals parla Cunillé són els internacionals: «Ya el mercado va a comenzar / y al mercado pienso yo ir, / que aunque nada vaya a comprar / por costumbre voy siempre allí. / Me gusta oír al vendedor / su mercancía pregonar. / Me gusta ver al comprador / regatear». L'Activista acompanya amb les maraques, i el Marit fa soroll amb una cassola. 
El Banquer admet que va arribar a governador del Banc d'Espanya per pura inèrcia i doblegant cada dia l'esquena en tots els mercats globals i internacionals. Mentre ells dos estan entretinguts amb el cant i la conversa, l'Activista es disposa a preparar-li un cafè al seu germà, el Marit, però no troba sinó l'urna embolicada amb la bandera britànica $i$ interpreta que el que hi ha a dins és te anglès; escalfa l'aigua i prepara sense saber-ho una poció amb les cendres de Margaret Thatcher. El Transvestit canta el cuplet La bolsa, explícita provocació al governador del Banc d'Espanya, súbdit de les pujades i baixades del mercat financer; recordem que per a l'espectacle Taxi... al TNC! (2013) Lluïsa Cunillé va adaptar la lletra original de Manuel Sugrañes, pertanyent a la revista Joy-Joy (1926): «Aquí amb un cop de sort, s'hi guanya molt, / cal invertir en accions, i en fons de pensions, / en hipoteques subprime, i en preferents, / cal especular ben fort i sense por». Més endavant, el taxista, penjant-se d'una corda i cobert de confeti, cantarà The show must go on.

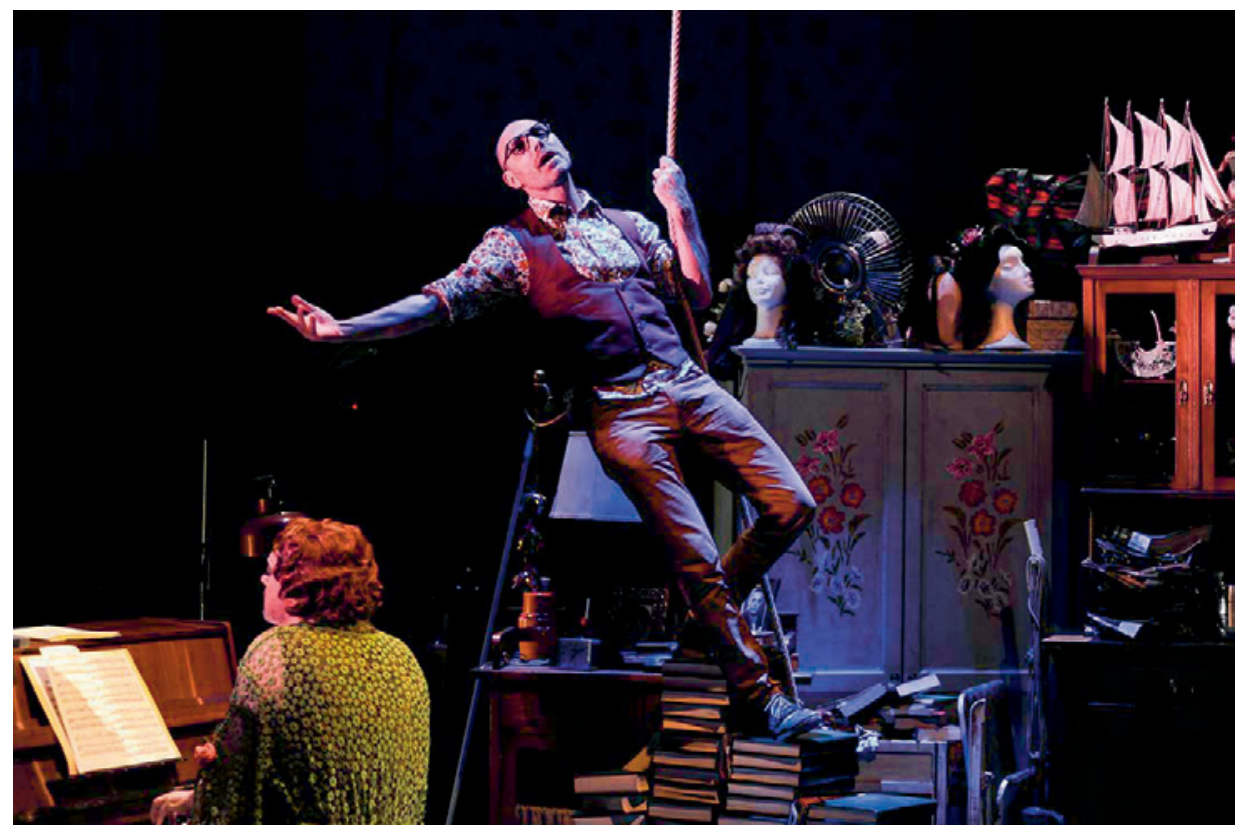

(C) Joan Tomàs/TNC.

El Marit comenta que el te que estan preparant és ben estrany, car es queda enganxat als imants de la nevera: «Deu ser un te ferruginós» (Cunillé 2015: 40). No poden sospitar que el que estan bullint no és te sinó les cendres -o les llimadures- de la Dama de Ferro. L'Activista li explica al seu germà que el seu pare, que va morir fa vint anys, li ha tornat a parlar i li ha dit que no es donin per vençuts; per això li demana que s'uneixi a la seva ONG contra els desnonaments, en què de fet ja només milita ella. Resulta com a mínim irònic que tan bon punt tastin el te -les cendres- es posin a parlar de morts i desapareguts. 
Es produeixen diàlegs paral-lels entre ambdues parelles de personatges. D'una banda, el Banquer i el Transvestit, a força d'anar bevent de la petaca del segon, van endinsant-se en el terreny de les confidències personals; de l'altra, els dos germans parlen de la família i dels seus valors i expectatives. El Transvestit surt a buscar canvi del bitllet de cinc-cents amb què el Banquer li ha pagat la classe de música; aquest es queda tocant el piano, i l'Activista agafa el megàfon i fa una nova crida a la ciutadania, sense el menor resultat.

El Marit li diu al Banquer que ha guanyat la loteria amb un número llarg, si bé no l'ha cobrat encara; tot això té un doble sentit, que es descobrirà a continuació: «En porto una còpia a sobre, el de debò el tinc ben guardat [...]. A un client li va fugir de la butxaca assegut al meu taxi [...]. La seva senyora juga a la loteria?» (Cunillé 2015: 48-49). En un habilíssim diàleg, a l'estil del cinema negre dels anys quaranta i cinquanta, ambdós homes fingeixen parlar d'un bitllet de loteria però tots dos saben que s'estan referint a una carta que li ha caigut al Banquer dins el taxi i que anava dirigida a la seva amant; el Marit està fent xantatge al Banquer, car l'amenaça de fer arribar la carta a la seva dona. Després que el Marit surt d'escena per anar al banc a cobrar el taló que li ha signat el governador del Banc d'Espanya, aquest agafa una tassa, es prepara un te amb les cendres de l'urna i hi aboca una mica d'alcohol de la petaca del Transvestit. Es beu la barreja d'un sol glop.

Entra la Veïna amb una perruca i un mocador al cap, i li demana consell al Banquer: vol un banc segur on guardar la perruca de la seva tia Margaret. El Banquer comença a sentir-se molt malament i cau desmaiat; aleshores entra l'Activista -que va fer d'infermera a la Seguretat Social fins que van començar a desmantellar-la- i, després de comprovar si el Banquer té pols, conclou que és mort. Troben la carta del Banquer a la seva amant, encara que només parla de la borsa, l'IBEX i els actius de risc. Com que cap de les dues vol tenir problemes amb la justícia, fiquen el cos dins la nevera desendollada, mentre la veïna xiula Downtown, el gran èxit de la britànica Petula Clark als anys seixanta. Per tal d'assegurar-se que el Banquer està mort del tot fiquen l'encenedor a la nevera, fet que remet deliberadament a la vetlla de Max Estrella a Luces de bohemia, en concret a l'escena tretzena, en què un cotxer proposava apropar un llumí al polze del difunt per comprovar si estava efectivament mort -ja en El bordell (2008) hi havia un homenatge a aquesta escena de Valle-Inclán-. Queda clar que El carrer Franklin es mou en el terreny de la farsa i juga amb el registre grotesc.

Arriba el Transvestit, furiós perquè el bitllet que li ha donat el governador és fals, però aleshores ha d'enfrontar-se a quelcom pitjor: el cadàver del governador dins la nevera. Els tres discuteixen sobre què han de fer amb el cos. Entra el Marit i, en saber que el Banquer és mort, trenca la carta, lamentant-se perquè el seu bitllet de loteria ha caducat abans d'hora. L'Activista els ofereix te ferruginós i planegen carregar entre tots el governador al taxi -«Ningú sospitarà que en un taxi xinès de segona mà hi vagi el governador del Banc d'Espanya» (Cunillé 2015: 65)- i llençar-lo al mar. El Marit obre la nevera i en treu l'anell del Banquer; després el Transvestit li pren el rellotge al cadàver, i l'Activista li agafa el talonari i el carnet d'identitat per copiar-li la firma. La Veïna deixa la 
perruca dins el refrigerador, agafa les ulleres de sol del Banquer i se les posa. L'Activista els serveix el te, que té una aroma estranya. Tots el tasten.

Després d'una pausa llarga, s'obre la nevera i el Banquer, amb la perruca de Thatcher posada $i$ amb un pot de quètchup a la mà a la manera de micròfon, comença a cantar sobre la música gravada de Nessu Dorma, ària del darrer acte de Turandot (1926) -òpera de Giacomo Puccini amb llibret de Giuseppe Adami i Renato Simoni-: «Nessun dorma! Nessun dorma! Tu pure, o Principessa, / nella tua fredda stanza / guardi le stelle / che tremano d'amore e di speranza [...] Dilegua, o notte! Tramontate, stelle! / Tramontate, stelle! All'alba vincerò! / Vincerò! Vincerò!». Els altres personatges el miren completament immòbils, com petrificats; acaben de comprendre que estan morts. Els han mort les cendres de Margaret Thatcher, que és com dir les conseqüències de la seva política de privatització i desregulació del capital.

El nom del carrer, genuïnament americà, $i$ les cendres de Margaret Thatcher situen l'obra en una línia de denúncia molt determinada -si bé de vegades pot semblar, com apunta Juan Carlos Olivares, que «la càrrega crítica quedi

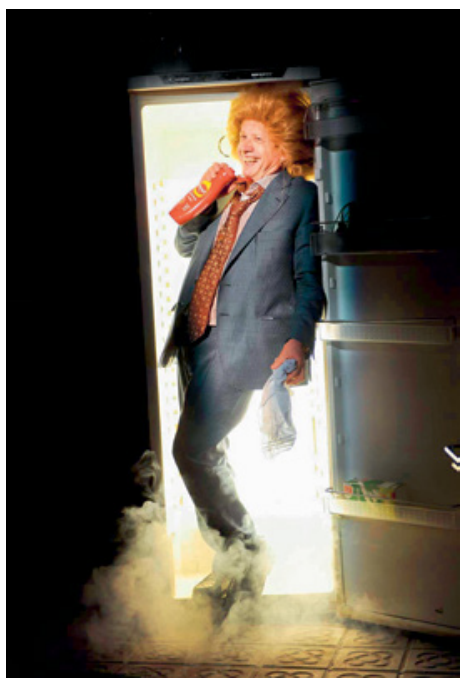

(C) Joan Tomàs/TNC. en un segon pla pel soroll que genera la festa i les seves particularitats» (Olivares 2015: 39)-. L'estratègia capitalista de Thatcher i Reagan va passar per descentralitzar el poder de l'Estat en benefici dels poders privats i va imposar una política devastadora per a l'acció pública: la desregulació bancària. Per això el que acaba matant els personatges d'El carrer Franklin són les cendres ferruginoses de la Dama de Ferro, perquè aquesta, en liberalitzar del tot les activitats econòmiques, va propiciar que el sector de les finances creixés exponencialment i va afavorir així el lucre d'una minoria a costa de l'explotació d'una majoria.

\section{A TALL DE CONCLUSIÓ}

El conjunt de la producció de Lluïsa Cunillé ofereix un catàleg de personatges, situacions i realitats dels nostres dies; una sèrie interminable d'instantànies que es refereixen tant a maneres, estratègies i mancances íntimes i relacionals com -cada cop més- a les decisions polítiques i les problemàtiques socials que condicionen la quotidianitat retratada. El seu teatre copsa moments, paisatges i besllums de l'Europa contemporània en diàleg amb el seu passat recent. En aquest sentit, assenyala Xavier Puchades que l'obra de Lluïsa Cunillé constitueix una mena de documental fotogràfic sobre la intimitat del ciutadà occidental (Puchades 2002: en línia); Xavier Albertí, per la seva banda, parla en termes de carta de navegació de la nostra contemporaneittat emocional (Albertí et al. 2005: 
63), i Fabrice Corrons considera que l'autora practica una dramatúrgia de la traça o del vestigi (Corrons 2009: 525).

En les seves obres més recents, Cunillé s'ocupa de temes com l'especulació immobiliària i la crisi econòmica, i la manera com el joc d'interessos de les entitats bancàries i l'avarícia personal dels seus dirigents han sumit la ciutadania en una situació crítica de difícil solució. Pensem, si no, en la tematització de l'economia borsària a Islàndia, i en el qüestionament que fa Dinamarca, en diàleg intertextual i metateatral amb Hamlet de William Shakespeare, de la societat del benestar. Es consolida, a més, una línia de teatre polític o compromès que vèiem ja en obres anteriors; així, a La cantant calba al Mc Donald's, retrat de la globalització i de la perplexitat i alienació que aquesta produeix, i en El bordell, en què es revisava el passat i la conjuntura històrica per tal d'il-luminar el present. D'altra banda, si a Islàndia i a Dinamarca es qüestiona la societat del benestar i la cèlebre felicitat d'escandinaus i nòrdics, Boira remet a un dels moments clau del segle XX, la caiguda del mur de Berlín, que va suposar la introducció del capitalisme al bloc oriental i va propiciar la globalització econòmica i cultural. Cal no oblidar tampoc els espectacles d'autoria compartida amb Xavier Albertí, tant les actualitzacions de sarsueles i operetes -El dúo de la Africana i La corte del Faraón-i del teatre de varietats -La Pajarera-com els collages escènics -Más extraño que el paraíso (2001) i PPP (2005), entre d'altres-, que vehiculen una certa crítica política i social, i també un cert revisionisme històric.

El compromís ètic es troba en totes i cadascuna de les obres de Lluïsa Cunillé, però hem volgut centrar-nos en Geografia i El carrer Franklin, perquè són les que més decididament han abordat qüestions de la més candent actualitat social i política. Geografia aborda els temes de la corrupció i del nepotisme, però també parla de la devaluació de la cultura i l'educació al nostre país. El carrer Franklin mostra una ciutat en què tothom ha estat desnonat i en què els ciutadans, lluny de l'activisme i la consciència social, malden per sobreviure; la peça denuncia en clau de farsa fins a quin punt de precarietat han conduït les polítiques neoliberals de les darreres dècades, produint un esvoranc social i condemnant una part de la ciutadania a la misèria i l'estancament.

En la seva producció més recent, Lluïsa Cunillé consolida i referma la voluntat de pensar -i de convidar l'espectador a pensar- de manera complexa els fenòmens del nostre món. La presència dels conflictes que caracteritzen la nostra societat i el compromís amb la realitat contemporània confirmen que l'univers de Lluïsa Cunillé no és un refugi autoreferencial ni endogàmic, construït a base de codis indesxifrables (Molner 2013: 25). Al contrari, cada cop més, amb el seu teatre, l'autora contribueix a explicar les lògiques que orquestren les transformacions del present social i històric, a través de les formes de vida material i el món psíquic dels seus personatges.

\section{BIBLIOGRAFIA}

Albertí, X. (2008) «Pròleg», dins: L. Cunillé Deu peces, Barcelona, Edicions 62 , pp. 9-12. 
Albertí, X. et al. (2005) «Fer Cunillé. Moments d'una conversa entre Xavier Albertí, Lurdes Barba, Lola López i Paco Zarzoso», DDT 05 (Documents de Teatre), Barcelona, Teatre Lliure, Societat Cooperativa, pp. 58-66.

Arribas, A. (2015) «El carrer de les persones lliures», dins: L. Cunillé El carrer Franklin, Tarragona, Arola Editors, pp. 7-8.

Batlle, C. (1999) «A manera de manifest: Lluïsa Cunillé i Maeterlinck», El Pou de Lletres, núm. K/11-L/12, pp. 46-47.

Corrons, F. (2009) Le théâtre catalan actuel (1980-2008): une pratique singulière?: l'étude de la relation théâtrale chez Sergi Belbel et Lluïsa Cunillé, deux auteurs de «l'Escola de Sanchis. Tesi doctoral dirigida per la Dra. Monique Martínez, Université Toulouse-Le Mirail.

Cunillé, L. (2014) Geografia, dins: R. Spregelburd + F. Richter + L. Cunillé Fronteres, Tarragona, Arola Editors, pp. 71-92.

- (2015) El carrer Franklin, Tarragona, Arola Editors.

Cunillé, L. + Zarzoso, P. (2012) El alma se serena, Valencia, Media Vaca.

Graell, V. (2014) «Fronteres, del Ecce Homo a la evasión de impuestos a Andorra», El Mundo, 14 de maig, p. 50.

Massip, F. (2004) «El teatre català actual: un balanç», Stichomythia: Revista de teatro español contemporáneo, núm. 2. <http://parnaseo.uv.es/Ars/ ESTICOMITIA/numero2/estudios/teatrecatala.pdf> [Data de consulta: 30 de maig de 2016.]

- (2013) «Panorama del teatre català des de final del segle XX fins a l'actualitat», Estudis escènics: quaderns de l'Institut del Teatre, núm. 39-40, pp. 207-265. <http://www.raco.cat/index.php/EstudisEscenics/article/ view/266831/354451> [Data de consulta: 30 de maig de 2016.]

Molner, E. (2013) «Atrapats a Cunillélandia», La Vanguardia. Culturas, 20 de febrer, p. 25.

Olivares, J. C. (2015) «El carrer Franklin», Time Out Barcelona, 6 de juliol, p. 39.

Prieto Nadal, A. (2013) «Entrevista a Xavier Albertí», Pausa, núm. 35, pp. 97-105. $<\mathrm{http}$ ://www.salabeckett.cat/fitxers/pauses/pausa-35/prieto-anna_entrevista-a-xavier-alberti> [Data de consulta: 12 d'octubre de 2015.]

- (2016) El teatro de Llü̈sa Cunillé. Claves y tendencias en su producción del siglo XXI (2000-2015), Madrid, Esperpento Ediciones Teatrales.

Puchades, X. (2002) «La memoria del presente: itinerario no definitivo por la obra de Lluïsa Cunillé», Stichomythia: Revista de teatro español contemporáneo, núm. 0. <http://parnaseo.uv.es/Ars/ESTICOMITIA/Numero0/ indicecero/a11.htm $>$ [Data de consulta: 12 d'octubre de 2015.]

Puig Taulé, O. (2014) «Una nit de teatre europeu», Núvol. El digital de cultura. $<$ http://www.nuvol.com/critica/una-nit-de-teatre-europeu> [Data de consulta: 26 de novembre de 2015]. 
Sala, C. (2014) «Spregelburd, Richter y Cunillé reflexionan sobre las fronteras», La Razón, 10 de maig, p. 5.

Serra, L. (2014) «El TNC se suma al debat de les Fronteres», Ara, 14 de maig, p. 36.

Sanchis Sinisterra, J. (2002) La escena sin límites, Ciudad Real, Naque Editora. 